\title{
Aislamiento e identificación de microorganismos del género Methanococcus y Methanobacterium de cuatro fuentes de Bogotá D.C.
}

\author{
Paola Andrea Acuña González', Lisvet Sofía Ángel García', \\ Elizabeth Borray Montoya ${ }^{1}$ Lucia Constanza Corrales², \\ Ligia Consuelo Sánchez ${ }^{2}$
}

\begin{abstract}
1. Bacteriólogas y Laboratoristas Clínicas Universidad Colegio Mayor de Cundinamarca 2. Msc. Docentes Programa de Bacteriología y Laboratorio Clínico, Facultad Ciencias de la Salud, Universidad Colegio Mayor de Cundinamarca

Recibido: 05/06/08 Aceptado: 10/08/08
\end{abstract}

Correspondencia: Icorralesr@unicolmayor.edu.co

\begin{abstract}
Resumen
Las bacterias metanogénicas obtienen su energía mediante la producción metabólica de gas metano, utilizando sustratos como dióxido de carbono, acetato y sustratos de metilo a través de procesos de hidrólisis y acetogenesis y son esenciales en la degradación anaerobia de la materia orgánica en la naturaleza. El propósito de esta investigación fue aislar bacterias metanogénicas para conservarlas en la colección de cultivos de la Universidad Colegio Mayor de Cundinamarca. El muestreo se realizó por duplicado de cuatro fuentes ubicadas en Bogotá D.C, Colombia, las cuales ofrecían las características ambientales para su desarrollo. El procedimiento incluyó la toma de la muestra en ambiente anaerobio, aislamiento en medios selectivos e identificación por observación de las características microscópicas con coloración de Gram y de características macroscópicas en los medios selectivos y verificación de producción de metano mediante prueba piloto. Los resultados permitieron evidenciar la presencia de bacterias de los géneros Methanococcus y Methanobacterium a partir de las fuentes seleccionadas para el estudio. Se concluyó que el mejor método para la conservación de estos géneros es la congelación con la adición de agentes reductores y glicerol como criopreservante.
\end{abstract}

Palabras clave: bacterias metanogénicas, anaerobiosis, producción de metano, simbiosis metabólica.

\section{Abstract \\ Isolation and identification of methanococcus and methanobacterium microorganisms from four different sources in Bogota, D. C}

Methanogenic bacterium get their energy through metabolic production of marsh gas, using substratums like carbon dioxide, acetate and methyl substratums. Metabolic production is done through processes of hydrolysis and acetogenesis which are essentials in the anaerobic degradation of the organic materia in nature. The purpose of this research was to isolate methanogenic bacterium to preserve them in the Universidad Colegio Mayor de Cundinamarca' cultivation collection. The sampling were done duplicated in four different sources located in Bogotá 
D.C, Colombia, which offered the environmental characteristics for their groth. The procedures followed included the sample taking in an anaerobic environment, isolating, in selective recipe and identification of the microscopic characteristics with Gram's coloration, macroscopic characteristics in the selective media and verification of methane through a sample. The final results allowed evidencing bacteria's presence such as Methanococcus and Methanobacterium from the sources selected for the study. It was concluded that the best method for the conservation of these species is freezing these samples with the addition of reducing agents and glycerol which acts as a criopreservante.

Key words: methanogenic bacterium, anaerobiosis, methane production, metabolic symbiosis.

\section{Introducción}

Las bacterias metanogénicas (Arqueas productoras de metano) están ampliamente distribuidas en la naturaleza en ambientes anoxigénicos; con mayor frecuencia se encuentran en ambientes terrestres como microambientes de poro medio en suelos, en bosques y praderas, aguas continentales, en especial en pantanos y zonas encharcadas $y$, en alguna proporción, en el mar $(1,2)$. Este último ambiente les genera competencia con microorganismos reductores de sulfatos por el acetato y el hidrógeno disponibles para su supervivencia, sustratos que pueden ser reemplazados por las metilaminas, excretadas por algunos animales marinos (3). En el suelo, agua y otros ambientes como el rumen, la disponibilidad de los sustratos depende de la acción metabólica de otros microorganismos que degradan compuestos orgánicos a acetato, formiato, metilamina, metanol y metilmercaptano entre otros. Estos son utilizados por las bacterias metanogénicas en la producción de metano.

Existen varios grupos de bacterias metanogénicas que se diferencian entre si por su morfología; se pueden encontrar bacilos y cocos filamentosos, agrupados en cadenas, diplococos, tetradas y racimos. Pueden desarrollarse a temperaturas que van desde a $38^{\circ} \mathrm{C} \mathrm{a} 75^{\circ} \mathrm{C}$ y su afinidad al Gram es variable (4). Su metabolismo se caracteriza por integrar las vías biosintéticas y bioenergéticas para la producción de ATP. En condiciones de ausencia de hidrógeno, oxidan compuestos para la obtención de electrones (5). Estas bacterias permiten ser empleadas en diferentes procesos biotécnológicos en sistemas anaerobios: como componente de biorreactores para descomposición de basura orgánica (6), para la producción de gas metano a partir de estiércol de cerdo (7); como modelo experimental en simulación de suelos de otros planetas (8), entre otros.

Los sistemas anaerobios desarrollan procesos fermentativos de los cuales se obtienen productos finales estables y una producción celular muy baja, alrededor del $3 \%$ de la materia orgánica presente en el agua residual es convertida en masa celular y el $97 \%$ restante es convertido por catabolismo en $\mathrm{CH}_{4}$ y $\mathrm{CO}_{2}$ como productos finales estables (9).

Teniendo en cuenta la importancia de estos microorganismos en los procesos de bioremediación para la conservación del medio ambiente, este estudio planteó como objetivo el aislamiento y fenotipificación de dos géneros de bacterias metanogénicas (Methanobacterium y Methanococcus) a partir de cuatro fuentes naturales, utilizando dos medios selectivos (Barker - Taha y Stadtman - Barker) respectivamente, y con el propósito de conservarlas en el cepario de la Universidad Colegio Mayor de Cundinamarca.

\section{Materiales y métodos}

\section{Recolección y obtención de las muestras}

Se realizó un muestreo por duplicado con jeringas estériles de $60 \mathrm{~mL}$, introduciéndolas aproximadamente a $40 \mathrm{~cm}$. por debajo del espejo de agua de tres fuentes seleccionadas: Humedal de Córdoba, aguas estancadas del Lago Timiza, canal de aguas residuales de la Avenida 127 (Bogotá), y contenido ruminal de un bovino sacrificado en el frigorífico de San Martín, el cual se tomó haciendo punción de la panza del animal sacrificado. Todas las 
Tabla 1. Reactivos utilizados para la preparación de $1000 \mathrm{~mL}$ del medio Methanobacterium (Barker-Taha)

\begin{tabular}{lr}
\hline Etanol & $10 \mathrm{~mL}$ \\
Fosfato dipotsico & $5 \mathrm{~g}$ \\
Sulfato de magnesio $7\left(\mathrm{H}_{2} \mathrm{O}\right)$ & $0.1 \mathrm{~g}$ \\
Sulfato de amonio & $0.3 \mathrm{~g}$ \\
Sulfato ferroso $7\left(\mathrm{H}_{2} \mathrm{O}\right)$ & $0.02 \mathrm{~g}$ \\
Autolisado de levadura & $5 \mathrm{~mL}$ \\
Carbonato de calcio & $100 \mathrm{~g}$ \\
Agua destilada & $1000 \mathrm{~mL}$ \\
\hline
\end{tabular}

muestras se mantuvieron en condiciones anaerobias inmediatas utilizando un tapón de caucho en cada jeringa para evitar la entrada de oxigeno $(4,7)$.

\section{Verificación de presencia de microorganismos en las muestras}

Se realizaron coloraciones de Gram de las muestras directas de las cuatro fuentes para verificar por microscopía la presencia de bacterias.

\section{Aislamiento y obtención de los microorganismos}

Los medios selectivos utilizados para el aislamiento fueron Barker-Taha $(M B)$ para Methanobacterium y Stadtman-Barker (MC) para Methanococcus (10). Estos medios incluyen diversos sustratos que son utilizados por estos microorganismos como fuente de energía para su crecimiento y metabolismo, Tabla 1 y 2 .

La preparación del medio (MB) requiere que una vez se esterilice, se le añaden las siguientes soluciones: carbonato de sodio $0.50 \mathrm{~g}$ en $10 \mathrm{~mL}$ de agua destilada y sulfuro de sodio $9\left(\mathrm{H}_{2} \mathrm{O}\right) 0.1 \mathrm{~g}$ en agua destilada $10 \mathrm{~mL}$.

Pre-reducción de los medios: para los medios líquidos, la pre-reducción se hizo mediante choque térmico, durante 10 minutos a a $100^{\circ} \mathrm{C}$ en baño maría y luego se enfriaron en chorro de agua fría con el fin de desplazar el $\mathrm{O}_{2}$ que pudiera encontrarse en el tubo. La pre-reducción de los agares se realizó dejando los medios por 2 horas en la jarra de anaerobiosis, utilizando los generadores de atmósfera (AnaeroGen OXOID) (11). A la prueba de esterilidad se le hizo un seguimiento de 72 horas para descartar contaminación con microorganismos aerobios y prueba de selectividad para verificar el desarrollo de bacterias anaerobias, con la inoculación de Clostridium spp. como control.
Tabla 2. Reactivos utilizados para la preparación de $1 \mathrm{~L}$ de medio Methanococcus (Stadtman-Barker).

\begin{tabular}{lr}
\hline Formiato de sodio & $15 \mathrm{~g}$ \\
Sulfato de amonio & $1 \mathrm{~g}$ \\
Cloruro de calcio & $0.01 \mathrm{~g}$ \\
Cloruro de magnesio & $0.01 \mathrm{~g}$ \\
Cloruro férrico & $0.02 \mathrm{~g}$ \\
\hline Sulfato de magnesio & $0.01 \mathrm{~g}$ \\
Molibdato de sodio & $0.001 \mathrm{~g}$ \\
Fosfato dipotásico & $2 \mathrm{~g}$ \\
Rojo de fenol & $0.003 \mathrm{~g}$ \\
\hline Azul de metileno & $0.002 \mathrm{~g}$ \\
\hline Tioglicolato de sodio & $0.5 \mathrm{~g}$ \\
\hline
\end{tabular}

Inoculación de la muestra: se inocularon $100 \mu \mathrm{L}$ de cada muestra en los medios líquidos para Methanococcus y Methanobacterium; se realizó coloración de Gram para verificar la presencia de bacterias; los cultivos se incubaron durante 15 días a $37^{\circ} \mathrm{C}$ en atmósfera de anaerobiosis (AnaeroGen - OXOID). A los 15 días se verificó el crecimiento bacteriano por turbidez en el medio y se realizó la siembra en los medios sólidos $\mathrm{MC}$ y MB pre-reducidos; se incubaron durante 15 días a $37^{\circ} \mathrm{C}$ en condiciones de anaerobiosis y se verificó la presencia de bacilos y cocos en el crecimiento obtenido en los medios líquidos y en los medios sólidos mediante coloración de Gram.

\section{Identificación fenotípica y producción de gas metano}

El aislamiento de colonias en los medios sólidos $\mathrm{MCy}$ $\mathrm{MB}$ confirmaron la presencia de bacterias metanogénicas. La verificación de la producción metabólica de gas metano, se realizó mediante la esterilización previa de cada uno de los elementos que componían el sistema de producción de metano: tubos $16 \times 150 \mathrm{~mm}$ con desprendimiento lateral, tapones de caucho, mangueras en látex de 20 $\mathrm{cm}$. y pinzas en garra. Posteriormente en cabina de 囚ujo laminar se armó el sistema, se envasó el medio de cultivo y se inoculó antes de sellar el sistema.

Los medios de cultivo utilizados fueron $\mathrm{MC}$ y $\mathrm{MB}$ líquidos en cantidad de $6 \mathrm{~mL}$ para proporcionar espacio suficiente para el almacenamiento del gas producido por las bacterias. El inóculo provino de las colonias obtenidas en los medios sólidos MC y MB debido a que la biomasa bacteriana obtenida en ellos fue mayor que en los medios 
Tabla 3. Resultados Gram directo

\begin{tabular}{cl}
\hline MUESTRA & \multicolumn{1}{c}{ GRAM } \\
Humedal & Bacilos Gram (-) \\
& Bacilos Gram (+) \\
& Cocos Gram (+) \\
& Bacilos Gram (-) \\
Lago & Cocos Gram (+) \\
& Bacilos Gram (-) curvos \\
Canal & Espiroquetas Gram (+) \\
& Bacilos Gram (+) \\
& Cocos Gram (+) \\
Rumen & Bacilos Gram (+) esporulados \\
\hline
\end{tabular}

líquidos. La medición cualitativa se hizo por la técnica de desplazamiento de agua contenida en la probeta $(12,13)$, evidenciado por la producción de burbujas generadas por el gas y el aumento del volumen final del agua. El objetivo de utilizar este sistema fue controlar la posible pérdida del gas producido por las bacterias durante la incubación y verificar la presencia del gas metano.

\section{Resultados}

\section{Verificación microscópica}

La morfología encontrada en el Gram directo de las muestras fue variada. La Tabla 3 se muestra los datos correspondientes a esta etapa.

\section{Aislamiento y obtención de los microorganismos}

Los datos obtenidos del aislamiento bacteriano en los medios líquidos y sólidos $\mathrm{MC}$ y $\mathrm{MB}$ indicaron crecimiento de bacterias con características compatibles con Methanococcus y Methanobacterium. La verificación morfológica mediante coloración de Gram se presentan en las Tablas 4 y 5 .

Las características macroscópicas de las colonias obtenidas en los agares fueron las siguientes: en el agar MC para Methanococcus se observó la presencia de colonias puntiformes, pequeńas de color amarillo pálido y en el agar MB para Methanobacterium las colonias que crecieron fueron redondas grandes, pegajosas, brillantes, que toman el color del medio (café). En las Figura 1 y 2 se observan las colonias obtenidas en los agares $\mathrm{MC}$ y $\mathrm{MB}$.
Tabla 4. Resultado Gram de caldo MC y MB

\begin{tabular}{ccl}
\hline MUESTRA & MC & MB \\
Humedal & No se observaron & Bacilos Gram (-) \\
Lago & Cocos Gram (+) & Bacilos Gram (-) \\
Canal & Cocos Gram (+) & Bacilos Gram (+) \\
Rumen & No se observaron & Bacilos Gram (+) \\
\hline
\end{tabular}

Tabla 5. Resultado Gram de los agares MC y MB.

\begin{tabular}{ccl}
\hline $\begin{array}{c}\text { MUESTRA } \\
\text { Humedal }\end{array}$ & MC & MB \\
Lago & No se observaron & Bacilos Gram (-) \\
& & \\
Canal & Cocos Gram (+) & No se observaron \\
Rumen & No se observaron & No se observaron
\end{tabular}

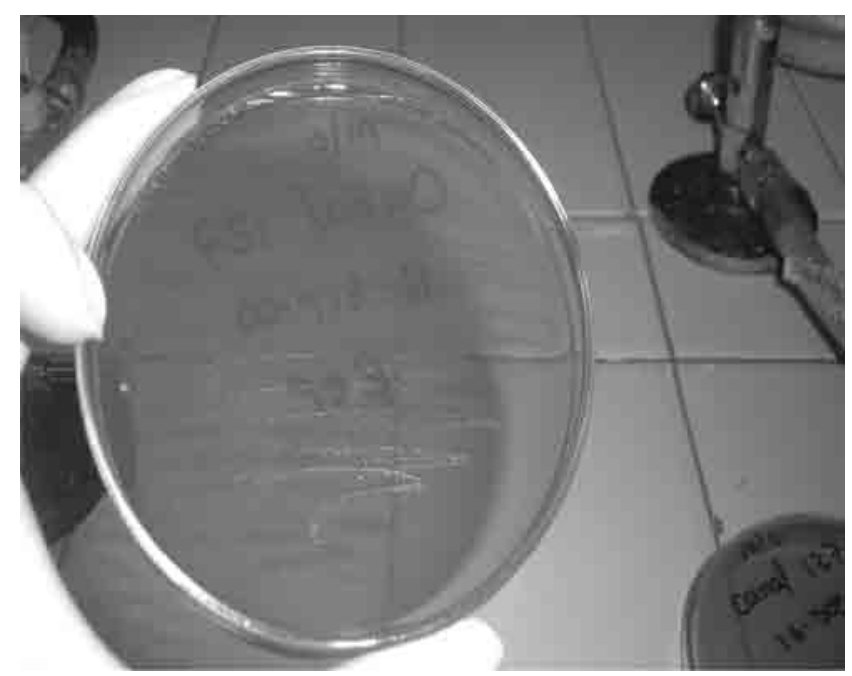

Figura 1. Colonias obtenidas en el agar MC. (Muestra canal de aguas Av. 127).

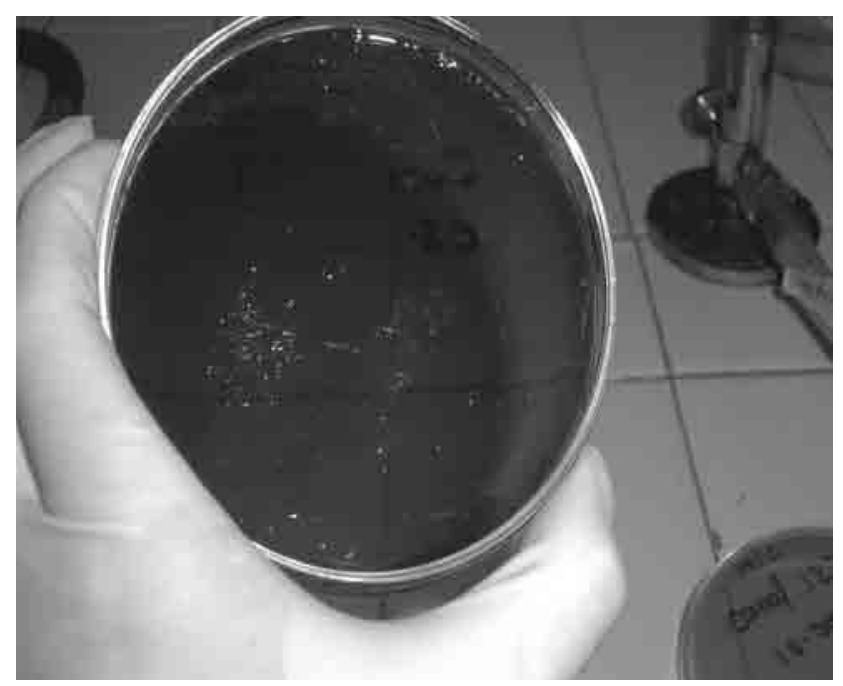

Figura 2. Colonias obtenidas en el agar MB. (Muestra aguas de Lago Timiza). 


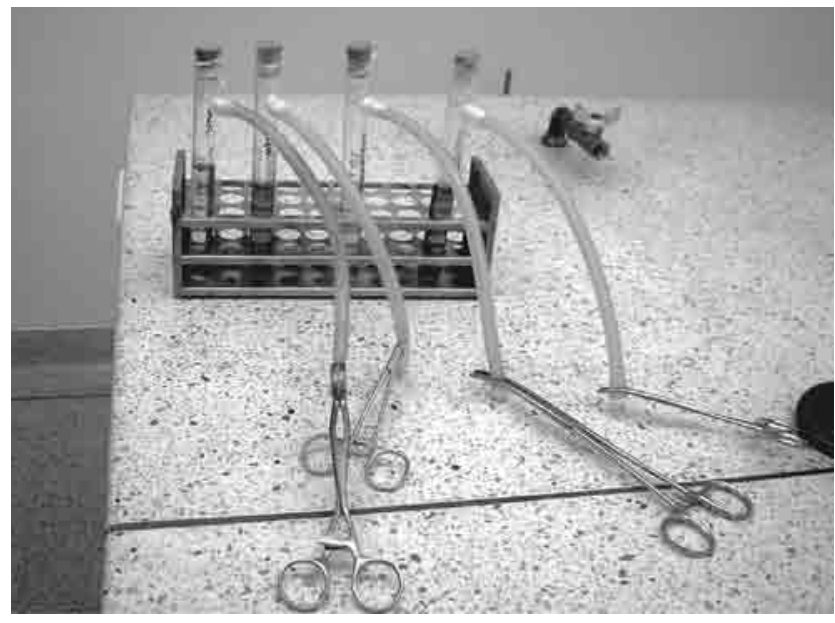

Figura 3. Montaje realizado para la comprobación cualitativa de metano.

Los medios selectivos empleados (Methanococcus Stadtman-Barker y Methanobacterium Barker-Taha) permitieron evaluar el crecimiento de bacterias metanogénicas aunque no se obtuvo crecimiento óptimo a partir de todas las muestras analizadas (14).

\section{Producción de gas metano}

La capacidad metabólica de los microorganismos para producir metano se verificó por el aumento del volumen del agua en las probetas, que es directamente proporcional al gas producido por los microorganismos aislados Methanococcus y Methanobacterium, Figura 3 y 4.

En el montaje que correspondía al medio MC del canal de aguas de la Av. 127 se observó un aumento de $3 \mathrm{~mL}$ del volumen de agua; pero no en el medio $\mathrm{MB}$ de la misma muestra. Se obtuvo un aumento de $2 \mathrm{~mL}$ del volumen de agua en el montaje del medio MB de la muestra de aguas estancadas del Lago Timiza y no el medio MC de la misma muestra. Tampoco hubo aumento del volumen de agua en los montajes realizados para el Humedal de Córdoba de los medios MC y MB, Tabla 6.

\section{Discusión}

Esta investigación permitió aislar bacterias metanogénicas de las fuentes seleccionadas, que crecieron en los medios específicos líquidos y sólidos $\mathrm{MC}$ y $\mathrm{MB}$ y se detectó en el experimento la producción del gas. También se corroboró que las bacterias metanogénicas no se encuentran solas en sus ambientes naturales,

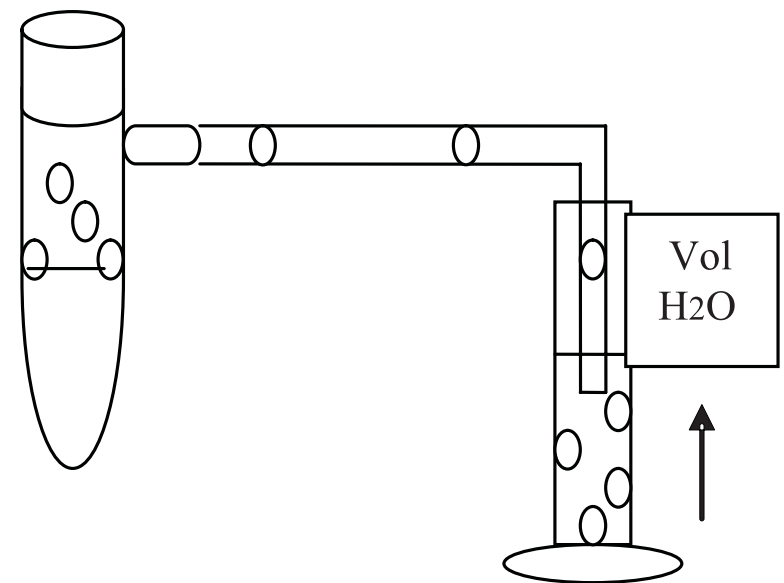

Figura 4. Representación esquemática del desplazamiento de agua por burbujeo.

Tabla 6: Desplazamiento de agua producido a partir de las diferentes muestras inoculadas en $M C$ y $M B$.

\begin{tabular}{ll}
\hline MUESTRA & DESPLAZAMIENTO DE AGUA \\
Canal Av. 127 & MC: $3 \mathrm{~mL}$ \\
& MB: Indetectable \\
Lago Timiza & MC Indetectable \\
& MB: $2 \mathrm{~mL}$
\end{tabular}

Humedal de Córdoba MC-MB: Indetectable

sino que sobreviven gracias a la simbiosis metabólica con otras, que le brindan sustratos esenciales para la producción de energía, aspecto que se ve re冈ejado en la evaluación microscópica con coloración de Gram a partir de las muestras directas, las cuales reportaron una gran variedad morfológica, diferente a bacilos y cocos que son las morfologías compatibles con el Methanococcus y Methanobacterium.

En la muestra del Humedal de Córdoba se vio crecimiento de bacilos Gram positivos en el caldo MB pero no hubo crecimiento en el caldo MC. Sin embargo, al hacer el aislamiento en medio sólido $\mathrm{MC}$ hubo crecimiento escaso de cocos Gram positivos. En el medio sólido MB crecieron bacilos Gram negativos que se habían evidenciado en el caldo. Estos resultados pueden ser explicados por la baja biomasa obtenida en el medio líquido relacionada con la dificultad para la adaptación y el desarrollo de estos microorganismos in vitro. 
El crecimiento bacteriano obtenido del rumen en los medios líquidos $\mathrm{MC}$ y $\mathrm{MB}$ tiene el mismo comportamiento al del Humedal de Córdoba. Sin embargo, al hacer el aislamiento en los medios sólidos, no se logró recuperar ningún microorganismo. Este resultado parece estar relacionado con la calidad de toma de muestra ya que estos microorganismos son sensibles a la presencia de oxígeno, así sea en muy bajas proporciones $(0.5-2 \%)$ o por tiempos cortos, factor que induce procesos de intoxicación y muerte bacteriana, supuesto que se sustenta en que al tomar la muestra del rumen, la panza del animal sacrificado estaba rota y el tiempo que transcurrió entre esta toma y la introducción de éste en la jeringa fue prolongado. La baja biomasa obtenida a partir de la muestra del rumen en los medios líquidos y la ausencia de crecimiento en los medios sólidos conllevó a descartar esta muestra dentro del estudio.

La morfología obtenida en los Gram de ambos caldos, MC y MB presenta concordancia con la selectividad según el fundamento del medio, además las estructuras observadas son características de las Archaeas Metanogénicas (5). Aunque en los protocolos establecidos por Chantereau (9) para el cultivo de los géneros Methanobacterium y Methanococcus, refiere que el crecimiento se puede obtener después de 7 días a partir de la inoculación en los medios de cultivo, en este trabajo se evidenció que los microorganismos pertenecientes a estos géneros son de crecimiento lento, estableciéndose como tiempo óptimo de desarrollo 15 días.

Las bacterias metanogénicas ofrecen una gran variedad de aplicaciones biotecnológicas si se tiene en cuenta que degradan gran variedad de desechos (solas o en consorcios). También son de interés industrial ya que a partir de materiales de desecho producen gas metano, útil porque genera energía al ser usado como combustible. A partir del estudio se plantean posibilidades de aplicación como en rellenos sanitarios, en los cuales se siembran con otras bacterias para generar este gas, combustible que puede ser utilizado para el propio mantenimiento de las instalaciones del relleno, posibilidad que se puede reproducir en otros sistemas como el de fangos activados para el tratamiento de aguas residuales, entre otros. Teniendo en cuenta su importancia y los resultados obtenidos en esta investigación, se puede anotar que la mejor forma de conservarlas en el cepario de la Universidad Colegio Mayor de Cundinamarca, para posteriores estudios, es por congelación con glicerol dada su vulnerabilidad a los ambientes aeróbicos y a las condiciones in vitro.

\section{Agradecimientos}

Los autores expresan sus agradecimientos a la Universidad Colegio Mayor de Cundinamarca, especialmente al Laboratorio Central por el suministro de reactivos, materiales y equipos para la realización de este proyecto, a los Ingenieros y trabajadores del Frigorífico de San Martín que amablemente nos abrieron sus puertas y nos colaboraron en la toma de la muestra del rumen bovino y a Laboratorios Quimirel por su amable colaboración para la consecución de productos necesarios para la investigación de anaerobios.

\section{Referencias}

1. Woese C, Wolfe S, Balch E. Methanogens: reevaluation of a unique group. Microbiol Rew 1979;43:260-296.

2. Balch E, Wolfe S. New Approach to the cultivation of methanogenic bacteria: 2-mercaptoethanesulfonic acid (HS-COM) dependent grow of Methanobacterium Ruminantium in a pressurized atmosphere. Appl Environ Microbiol 1976;32:781-791.

3. Fredrickson JK, Onstott TC. Vida en las profundidades de la Tierra. Investigación y Ciencia 2003;243:22-28.

4. Rittmann B. Biotecnología del Medio Ambiente: principios y aplicaciones, Ed. Mc GrawHill 2000.

5. Madigan M, Martinko J, Parker J. Biología de los Microorganismos, Madrid. 8 Ed. Prentice Hall, 2000.

6. Mertoglu B, Calli B, Guler N, Inanc B, Inoue Y. Effects of insufficient air injection on methanogenic Archaea in landfill bioreactor. J Hazard Mater. 2007;42:258-265.

7. Padmasiri SI, Zhang J, Fitch M, Norddahl B, Morgenroth E, Raskin L. Methanogenic population dynamics and performance of an anaerobic membrane bioreactor (AnMBR) treating swine manure under high shear conditions. Water Res. 2007;41:134-144.

8. Ormond DR, Kral TA. Washing methanogenic cells with the liquid fraction from a Mars soil simulant and water mixture. J Microbiol Methods. 2006;67:603-605.

9. Noyola A .Tratamiento anaerobio de aguas residuales. Foro Internacional. Comparación de dos tecnologías en Aguas residuales domésticas para municipalidades. Universidad Nacional de Medellín, Colombia: 1997; 40 pp.

10. Chantereau J. Corrosión Bacteriana, México Ed. Limusa 1985.

11. Miller PH, Wiggs LS, Miller JM. Evaluation of AnaeroGen system for growth of anaerobic bacteria. J Clin Microbiol. 1995;33:2388-2391.

12. Restrepo F, Restrepo J, Vargas L. Química Básica, Medellín Vol 2, Ed Susaeta, 1978.

13. Restrepo F, Restrepo J. Química, Medellín Tomo II, Ed Susaeta, 1992.

14. Smith PH, Hungate RE. Isolation and characterization of Methanobacterium ruminantium n. sp. J Bacteriol. 1958;75:713-718. 